\title{
Revisiting the Environmental Impacts of Railway Transport: Does EKC Exist in South-Eastern Europe?
}

\author{
Sadeq J. Abul ${ }^{1}$, Elma Satrovic ${ }^{2 *}$ \\ ${ }^{1}$ Independent Economic Advisor, Kuwait \\ ${ }^{2}$ University of Novi Pazar, Serbia
}

Received: 23 May 2021

Accepted: 17 August 2021

\begin{abstract}
This study explores passenger railway transport to enrich the research on the environmental Kuznets curve (EKC) hypothesis for a group of ten Southeastern Europe (SEE) countries, based on annual data for the period 1995 to 2014. The research results suggest that there exists a long-term, stable linkage among the observed variables. The legitimacy of the transport-induced EKC hypothesis is affirmed in the long-term in the SEE countries using the panel autoregressive distributed lag (ARDL) of the pooled mean group (PMG) and fully modified ordinary least square (FMOLS). Additionally, the evidence highlights the presence of the transport-induced EKC hypothesis only in the case of Croatia and Turkey in the short-term. Furthermore, it was detected that affluence, fossil fuel energy consumption, railway transport and urbanization drive environmental damage. The findings further suggest two-way causal relationship between transport activity and environmental depletion. Herein, the railway transportation system of the SEE countries does not help to reduce the level of carbon emissions.
\end{abstract}

Keywords: environmental Kuznets curve, fossil fuel energy consumption, railway transport, Southeastern Europe, urbanization

\section{Introduction}

The rapid growth of the world economy, along with the even faster rise of international trade, has contributed strongly to the development of the freight and passenger transportation sector. Transportation is a key activity of any economy and an essential component of human welfare all over the globe. However, various issues are connected with transportation, such as air pollution,

*e-mail: elma.satrovic@uninp.edu.rs traffic accidents, injuries, etc. In this study, special focus will be placed on air pollution. Transport remains dependent on a single fossil resource - petroleum that provides $95 \%$ of the total energy consumed by transportation worldwide [1]. Heat/electricity generation and transportation activity are responsible for more than $66 \%$ of the total carbon dioxide emissions [2].

The inverted U-shaped environmental degradationaffluence nexus is parallel to the inequality-income nexus proposed by Kuznets in 1955 [3] and later generalized as an environmental Kuznets curve (EKC) [4]. The EKC framework is a helpful instrument for addressing the environmental challenges caused by 
carbon emissions. It suggests a positive association between pollutant emissions and affluence during the initial phases of the growth process, but later an increase in affluence reduces pollutant emissions. Over time, the research community has widely debated the EKC phenomenon in a single country [5-13] or multiple countries [14-27].

The review of these studies shows that the EKC framework has been intensively used to describe the relationship between economic growth and pollutant emissions. Moreover, some of these studies further include energy consumption and other macroeconomic variables. In addition, these findings fail to provide consistent evidence of the validity of the transportinduced EKC hypothesis due to the explanatory variables used, empirical methodology or dataset. Despite the fact that the EKC hypothesis has been widely investigated in the recent literature, no studies have investigated the transport-induced EKC hypothesis for the sample of SEE countries alone. Hereinafter, the study on the transport-induced EKC phenomenon in SEE countries can unveil the role of railway transport in pollutant emissions and fill the present gaps in the literature.

Prior studies in the environmental depletiongrowth nexus popularly use per capita $\mathrm{CO} 2$ emissions as an adequate proxy for environmental depletion [6, 9, 14, 28-31]. The basic model of the EKC hypothesis suggests that economic growth has a great predictive ability for pollutant emissions. Basically, as the economic output increases, the intensified industry releases more greenhouse gases. This is perhaps due to the implementation of dirty technologies that increase environmental depletion. Hereinafter, many studies introduced real GDP per capita as a proxy for affluence [9, 11, 18]. Following the attempts in recent studies, we augmented the EKC hypothesis by focusing on the role of fossil fuel energy consumption. Following existing studies $[15,32,33]$, it can be concluded that the intensification of economic activities and industry boosts environmental depletion, since these sectors use fossil fuel energy consumption to foster growth. In particular, fossil fuel is an energy source that was traditionally used to meet the increasing energy demand, thereby causing greenhouse gasses emissions. The economic boom period may lead to the increased consumption of traditional energy from railway transportation, thereby hampering the environmental quality. Hence, [15] justify the use of (passenger) railway transport as a proxy for transport activities. Again, the economic boom increases the degree of urbanization, leading to fossil fuel energy consumption and consequently increasing the environmental depletion [7, 17].

Based on the above-discussed background, the main purpose of the present study is to answer the belowmentioned research questions (RQs):

- RQ1: Is there an occurrence of the inverted U-shaped pattern between affluence and carbon emissions in SEE countries?
- RQ2: Does railway transport affect the environmental quality in the context of SEE countries?

This study has two objectives. The first is to examine the long-term connection between the selected variables to explore whether or not environmental depletion tends to increase parallel to affluence and other macroeconomic indicators of pollutant emissions. The second objective is to check the causal linkage among the selected variables. Causality explains the priority and information content of affluence, urbanization, energy consumption and railway transport with regard to environmental depletion. Our study's hypothesis explores whether the transport-induced EKC framework holds in the case of SEE countries. In this context, the confirmation of the transport-induced EKC framework supports an inverted U-shaped relationship. However, the rejection of the transport-induced EKC framework would suggest a positive relationship between environmental depletion and affluence in the later stages of economic growth.

Henceforth, the novel contribution of this study to the existing body of knowledge may be elaborated as follows. Firstly, it examines for the first time the presence of the transport-induced EKC hypothesis for SEE countries alone. Secondly, this study is the first of its kind, to the best of our knowledge, to employ fossil fuel energy consumption as a proxy for energy consumption in the selected sample of countries. Moreover, we applied a panel VECM framework to examine the short- and long-term effects of the cointegrating vector. Finally, yet importantly, we introduce simultaneously both variables - fossil fuel energy consumption and railway transport - into the EKC theory.

The remainder of this study is organized as follows: Sections 2 and 3 define the study area, theoretical model, methodology and data, respectively. Section 4 interprets the main empirical outcomes. Section 5 provides the concluding remarks and underlines the policy implications of this research.

\section{Study Area}

This study assesses whether affluence, fossil fuel energy consumption, urbanization and railway transport caused environmental depletion under the EKC framework for SEE countries during the period 19952014. We study ten Southeastern Europe countries. The annual panel data used in this study cover the period 1995-2014. In a study from 1983, Jelavich included 13 countries in his classification of Southeastern Europe [34]. Data sourced from Southeastern Europe were inaccessible; hereinafter, our study considers the sample of the following countries: Albania, Bulgaria, Bosnia and Herzegovina, Greece, Croatia, Moldova, North Macedonia, Romania, Slovenia, and Turkey. The justification for the selection of Southeastern Europe (SEE) countries as the research's sample countries is 
twofold. Firstly, the cities and towns of the Western Balkans have some of the worst air quality in Europe. There are several reasons for the poor air quality in the selected countries; e.g., the strong reliance on coal for the production of electricity; the weak energy efficiency of buildings; heating; and industry [35]. An additional major source of air pollution is transport, especially in urban areas. The concentration of cars has increased in cities, together with the rapid urbanization. Vehicles made before 1990 can still be seen on the streets and their performance in terms of pollution is very poor. In addition, public transport suffers from under-investment and the quality of the fuel remains a concern. Secondly, although the transport-induced EKC framework has been widely examined in prior studies, no study has investigated this nexus in relation to SEE countries. Overall, SEE countries appear to be a highly appropriate sample of countries to verify the EKC phenomenon by addressing air pollution above the annual limit set by European Union legislation [35].

\section{Material and Methods}

In this study, we adopt the model to explore whether railway transport, economic growth, fossil fuel energy consumption and urbanization cause environmental depletion under the EKC theory using the case of ten SEE countries. The empirical linkage amid the variables of interest is specified as Equation (1):

$$
E D I=f\left(R G C, R G C^{2}, F F E C, R P C, U P T\right)
$$

Here, EDI represents the proxy for environmental depletion, while the real GDP per capita and the square of the real GDP per capita are denoted by RGC and $\mathrm{RGC}^{2}$ respectively, FFEC is the proxy for energy consumption, RPC is the indicator of railway transport activity, and UPT is the proxy for urbanization. To check the validity of the EKC hypothesis, we convert Eq. 1 into natural logarithms $[8,14,15,18]$ and the reconstructed model is formalized as (Eq. 2):

$$
\begin{gathered}
L(E D I)_{i t}=\alpha_{0}+\alpha_{1} L(R G C)_{i t}+\alpha_{2} L(R G C)_{i t}^{2} \\
+\alpha_{3} L(F F E C)_{i t}+\alpha_{4} L(R P C)_{i t}+\alpha_{5} L(U P T)_{i t}+\varepsilon_{i t}
\end{gathered}
$$

Here, the ten selected SEE countries are represented by $i$, which ranges between 1 and $N$, with $t$ denoting the time period and which ranges between 1 and $T$. The intercept of the model is represented by $\alpha_{0}$. The coefficients $\alpha_{1}-\alpha_{5}$ denote, respectively, the impact of affluence and its quadratic form, fossil fuel energy consumption, railway transport and urbanization on pollutant emissions. The regression error disturbance is presented by $\varepsilon_{i t}$ and $L$ stands for the natural logarithm.

Based on Eq. (2), the EKC hypothesis (an inverted U-shaped relationship) is confirmed when the coefficient of $L(R G C)$ displays a positive sign $\left(\alpha_{1}>0\right)$ and the coefficient of $L(R G C)^{2}$ has a negative sign $\left(\alpha_{2}<0\right)$. If both of these coefficients equal zero $\left(\alpha_{1}=\alpha_{2}=\right.$ $0)$, there is no evidence of the environmental depletiongrowth nexus; if $\alpha_{1}>0 ; \alpha_{2}=0$, there is a positive and linear relationship; if $\alpha_{1}<0 ; \alpha_{2}=0$, there is a negative and linear relationship. Lastly, $\alpha_{1}<0 ; \alpha_{2}>0$ suggest a U-shaped relationship between environmental depletion and growth.

Next, the transport-induced EKC hypothesis was analyzed by implementing the following five steps. First, we performed the cross-sectional dependence test proposed by Pesaran to check whether the selected panel data demonstrate considerable cross-sectional dependence [36]. Second, we assessed the stationary of each variable via the Levin et al.- LLC [37], PhillipsPerron-Fisher Chi-square - PPF [38] - and crosssectionally augmented Im-Pesaran-Shin (CIPS) [39]. The alternative assumes the stationary properties of at least one panel. Third, Kao residual cointegration [40], Johansen Fisher panel cointegration and Westerlund cointegration tests were performed to examine the possible cointegration in Eq. (2) [41, 42]. The common null hypothesis assumes no cointegration. It is worth mentioning that the Westerlund cointegration test is robust to cross-sectional dependence [42]. The Johansen-Fisher test created by Maddala and Wu seeks the number of stationary combinations that can be provided within the inspected variables [41]. Clearly, the failure of the trace test to reject the null hypothesis of at most five cointegration equations implies the existence of a cointegration relationship among the selected variables. Fourth, given the presence of cointegration, a long-term model was set up accordingly. To this end, two panel data techniques were utilized to examine the nexus of interest in the long-term: panel autoregressive distributed lag (ARDL) model with the pooled mean group (PMG) and fully modified ordinary least squares (FMOLS) estimators for the panel cointegration regression.

The transformed FMOLS estimator for the panel cointegration regression can eliminate any issue of serial correlation or endogeneity. Accordingly, a panel setting of the FMOLS model, formalized by Pedroni, is shown as Eq. (3) [43]:

$$
\beta_{F M O L S}=\left[\sum_{i=1}^{N} \sum_{t=1}^{T} X_{i t} X_{i t}^{\prime}\right]^{-1}\left(\sum_{i=1}^{N} \sum_{t=1}^{T} X_{i t} \bar{y}_{i t}^{+}-\gamma_{12}^{+\prime}\right)
$$

Here, $X_{i t}$ and $y_{i t}$ stand for the cointegrated variables. $\bar{y}_{i t}^{+}$displays the modification of the independent variables and the corrected serial correlation terms (i.e. $\bar{y}_{i t}^{+}=\left(y_{i t}-\bar{y}_{i}\right)-\widehat{w}_{12} \omega_{22}^{-1} \nabla_{22}$ where $\omega$ and $\nabla$ are represent the estimates of long-run covariances; $\left.\gamma_{12}^{+\prime}=r_{12}-\widehat{w}_{12} \omega_{22}^{-1} \Delta_{22}\right)$. The study [43] provides a brief description of the estimation procedure.

This study also employed the PMG estimator to evaluate the dynamic panel data model. This model enables us to reveal the short- and long-term relationships of the transport-induced EKC. Scholars 
The $A R D L(p, q, q, \ldots, q)$ model is used to propose the PMG estimator and can be formalized as Equation (4) [44]:

$$
L(E D I)_{i t}=\sum_{j=1}^{p} \theta_{i j} L(C O)_{i t-j}+\sum_{j=0}^{q} \rho_{i j} x_{i t-j}+\mu_{i}+u_{i t}
$$

...where $x_{i t}$ stands for the regressors $L(R G C), L\left(R G C^{2}\right)$, $L(F F C), L(R P C)$ and $L(U P T), \rho_{i j}$ is the vector of the respective regression coefficients, $\theta_{i j}$ denotes the regression coefficient with the lags of the dependent variable, $\mu_{i}$ is the fixed effects, and $u_{i t}$ is the general disturbance term. The short-run cointegration panel model can be represented as Eq. (5):

$$
\begin{gathered}
\Delta L(E D I)_{i t}=\alpha_{0}+\sum_{i=1}^{p} \theta_{i} \Delta L(E D I)_{t-i} \\
+\sum_{j=1}^{q} \delta_{j} \Delta L(R G C)_{t-j}+\sum_{m=1}^{q} \beta_{m} \Delta L\left(R G C^{2}\right)_{t-m} \\
+\sum_{r=1}^{q} \varphi_{r} \Delta L(F F E C)_{t-r}+\sum_{s=1}^{q} \sigma_{s} \Delta L(R P C)_{t-s} \\
+\sum_{u=1}^{q} \sigma_{u} \Delta L(U P T)_{t-u}+\tau E C T_{t-1}+\varepsilon_{i t}
\end{gathered}
$$

...where the lag length is denoted by $q$ and ECT is the error-correction term

Finally, the VECM Granger causality is utilized to observe the short- and long-term causality. Given that our variables are stationary at first differences and conintegrated, a Granger causality test within the panel VECM framework was applied to provide the directional relationships between the selected variables and differentiate between the short- and long-term Granger causality. Equations (1) and (2) can be reformulated into a VECM Granger causality equation for pollutant emissions from affluence, fossil fuel energy consumption, railway transport and urbanization, and formalized as (Eq. 6-11):

$$
\begin{gathered}
\Delta L(E D I)_{i t}=\vartheta_{1 i}+\sum_{m} \vartheta_{11 i m} \Delta L(E D I)_{i t-m} \\
+\sum_{m} \vartheta_{12 i m} \Delta L(R G C)_{i t-m}+\sum_{m} \vartheta_{13 i m} \Delta L\left(R G C^{2}\right)_{i t-m} \\
+\sum_{m} \vartheta_{14 i m} \Delta L(F F E C)_{i t-m}+\sum_{m} \vartheta_{15 i m} \Delta L(R P C)_{i t-m} \\
+\sum_{m} \vartheta_{16 i m} \Delta L(U P T)_{i t-m}+\tau_{1 i} E C T_{i t-1}+\varepsilon_{1 i t} \\
+\sum_{m} \vartheta_{22 i m} \Delta L(R G C)_{i t-m}+\sum_{m} \vartheta_{23 i m} \Delta L\left(R G C^{2}\right)_{i t-m} \\
+\sum_{m} \vartheta_{24 i m} \Delta L(F F E C)_{i t-m}+\sum_{m} \vartheta_{25 i m} \Delta L(R P C)_{i t-m} \\
+\sum_{m} \vartheta_{26 i m} \Delta L(U P T)_{i t-m}+\tau_{2 i} E C T_{i t-1}+\varepsilon_{2 i t}
\end{gathered}
$$

$$
\begin{aligned}
& \Delta L\left(R G C^{2}\right)_{i t}=\vartheta_{3 i}+\sum_{m} \vartheta_{31 i m} \Delta L(E D I)_{i t-m} \\
& +\sum_{m} \vartheta_{32 i m} \Delta L(R G C)_{i t-m}+\sum_{m} \vartheta_{33 i m} \Delta L\left(R G C^{2}\right)_{i t-m} \\
& +\sum_{m} \vartheta_{34 i m} \Delta L(F F E C)_{i t-m}+\sum_{m} \vartheta_{35 i m} \Delta L(R P C)_{i t-m} \\
& +\sum_{m} \vartheta_{36 i m} \Delta L(U P T)_{i t-m}+\tau_{3 i} E C T_{i t-1}+\varepsilon_{3 i t} \\
& \Delta L(F F E C)_{i t}=\vartheta_{4 i}+\sum_{m} \vartheta_{41 i m} \Delta L(E D I)_{i t-m} \\
& +\sum_{m} \vartheta_{42 i m} \Delta L(R G C)_{i t-m}+\sum_{m} \vartheta_{43 i m} \Delta L\left(R G C^{2}\right)_{i t-m} \\
& +\sum_{m} \vartheta_{44 i m} \Delta L(F F E C)_{i t-m}+\sum_{m} \vartheta_{45 i m} \Delta L(R P C)_{i t-m} \\
& +\sum_{m} \vartheta_{46 i m} \Delta L(U P T)_{i t-m}+\tau_{4 i} E C T_{i t-1}+\varepsilon_{4 i t} \\
& \Delta L(R P C)_{i t}=\vartheta_{5 i}+\sum_{m} \vartheta_{51 i m} \Delta L(E D I)_{i t-m} \\
& +\sum_{m} \vartheta_{52 i m} \Delta L(R G C)_{i t-m}+\sum_{m} \vartheta_{53 i m} \Delta L\left(R G C^{2}\right)_{i t-m} \\
& +\sum_{m} \vartheta_{54 i m} \Delta L(F F E C)_{i t-m}+\sum_{m} \vartheta_{55 i m} \Delta L\left(G D P^{2}\right)_{i t-m} \\
& +\sum_{m} \vartheta_{56 i m} \Delta L(U P T)_{i t-m}+\tau_{5 i} E C T_{i t-1}+\varepsilon_{5 i t} \\
& \Delta L(U P T)_{i t}=\vartheta_{6 i}+\sum_{m} \vartheta_{61 i m} \Delta L(E D I)_{i t-m} \\
& +\sum_{m} \vartheta_{62 i m} \Delta L(R G C)_{i t-m}+\sum_{m} \vartheta_{63 i m} \Delta L\left(R G C^{2}\right)_{i t-m} \\
& +\sum_{m} \vartheta_{64 i m} \Delta L(F F E C)_{i t-m}+\sum_{m}^{m} \vartheta_{65 i m} \Delta L\left(G D P^{2}\right)_{i t-m} \\
& +\sum_{m} \vartheta_{66 i m} \Delta L(U P T)_{i t-m}+\tau_{6 i} E C T_{i t-1}+\varepsilon_{6 i t}
\end{aligned}
$$

...where the first difference is depicted by $\Delta$ and $m$ displays the lag length. The VECM residual $\mathrm{s}$ erial correlation test is employed for the residual diagnostics.

The transport-induced EKC hypothesis was studied by considering six variables. The data on $\mathrm{CO}_{2}$ emissions, real GDP per capita, real GDP per capita squared, fossil fuel energy consumption and urban population were sourced from the World Bank Development Indicators Database 2020 [45], whereas those on the railways and the passengers carried were sourced from [45] and [46]. Table 1 presents the definition of each variable:

Environmental depletion was approximated using per capita metric tons carbon emissions - EDI. The impact of affluence is evaluated using per capita GDP (constant 2010 US\$) $-R G C$. Our study also introduces the squared term of per capita GDP (constant 2010 US\$) $-R G C^{2}$. Energy consumption is approximated using fossil fuel energy consumption as a percentage of the total - FFEC and urbanization using the urban population (\% of total population) - UPT. We augment the EKC phenomenon by analyzing the role of transport, utilizing railways and passengers carried $-R P C$. 
Table 1. List of variables and their description.

\begin{tabular}{|c|c|c|c|}
\hline Variable & Variable description & Unit & Source \\
\hline$E D I$ & CO2 emissions & Metric tons per capita & [45] (EN.ATM.CO2E.PC) \\
\hline$R G C$ & GDP per capita & Constant 2010 US\$ & [45] (NY.GDP.PCAP.KD) \\
\hline$R G C^{2}$ & GDP per capita squared & Constant 2010 US\$ & [45]; authors'calculations. (NY.GDP.PCAP.KD) \\
\hline$F F E C$ & Fossil fuel energy consumption & $\%$ of total & [45] (EG.USE.COMM.FO.ZS) \\
\hline$R P C$ & Railways, passengers carried & million passenger-km & [45]; [46] (IS.RRS.PASG.KM; PASSTRANSP) \\
\hline$U P T$ & Urban population & $\%$ of total population & [45] (SP.URB.TOTL.IN.ZS) \\
\hline
\end{tabular}

Source: $[45,46]$; authors' calculations.

\section{Results and Discussion}

\section{Statistical Summary}

Summary descriptive statistics and a correlation matrix of the variables can be seen in Table 2. The empirical results are estimated before employing a linear logarithmic model. According to the correlation matrix demonstrated in Table 2, it can be concluded that the correlation coefficients between $E D I$ and $R G C$, $R G C^{2}, F F E C$ and $U P T$ are reasonably high, positive and statistically significant. However, the correlation coefficient with $R P C$ is not statistically significant. In Table 2, the average value of all of the variables is positive. All of the variables except EDI and FFEC have a positive value of skewness, displaying the distribution skewed to the right.

Table 2 also demonstrates similar differences among the countries under inspection. The proxy variable for environmental depletion reports a maximum value for Greece (8.98) in 2005 and a minimum value for
Albania in 1997 (0.49). The maximum value of real GDP per capita is reported for Greece (30054.90) in 2007, while Bosnia and Herzegovina has the minimum value of 871.17 in 1995. In light of the proxy for energy consumption, Moldova reports the maximum fossil fuel energy consumption as a percentage of the total of 94.69 in 1995 and Albania the minimum value of 41.45 in 1997. Greece had the highest level of urbanization (\% total) in 2014 of 77.70 , whereas the minimum value pertains to Albania in 1995 (38.91). The railways and passengers carried reaches a maximum value for Romania in 1995 (18879) and a minimum value for Albania in 2014 (8).

\section{Cross-Sectional Dependence and Stationarity}

With the aim of contributing to the empirical research on the validity of the transport-induced EKC phenomenon, this study employs the methodology highlighted in Section 2 using the case study of ten SEE countries for the period 1995-2014. Initially, we test

Table 2. Descriptive Statistics Results and the Correlation Matrix.

\begin{tabular}{|c|c|c|c|c|c|c|}
\hline Var./Stat. & EDI & RGC & $\mathrm{RGC}^{2}$ & FFEC & RPC & UPT \\
\hline EDI & 1 & & & & & \\
\hline RGC & $0.750^{* * *}$ & 1 & & & & \\
\hline $\mathrm{RGC}^{2}$ & $0.713^{* * *}$ & $0.969^{* * *}$ & 1 & & & \\
\hline FFEC & $0.237^{* * *}$ & 0.065 & 0.093 & 1 & & \\
\hline RPC & 0.057 & -0.034 & -0.103 & $0.196^{* * *}$ & 1 & \\
\hline UPT & $0.586^{* * *}$ & $0.501^{* * *}$ & $0.449^{* * *}$ & $0.249^{* * *}$ & $0.245^{* * *}$ & 1 \\
\hline Mean & 4.68 & 9246.27 & 145000000.00 & 80.41 & 2197.45 & 56.40 \\
\hline St dev & 2.21 & 7703.71 & 215000000.00 & 10.99 & 3207.96 & 10.79 \\
\hline Max & 8.98 & 30054.90 & 903000000.00 & 94.69 & 18879.00 & 77.70 \\
\hline Min & 0.49 & 871.17 & 758930.30 & 41.45 & 8.00 & 38.91 \\
\hline Skew & -0.010 & 1.118 & 1.785 & -0.884 & 2.582 & 0.373 \\
\hline Kurtos & 2.172 & 3.049 & 5.179 & 3.499 & 11.109 & 1.969 \\
\hline
\end{tabular}

Note: Significance levels: ${ }^{*} \mathrm{p}<10 \%,{ }^{* *} \mathrm{p}<5 \%,{ }^{* * *} \mathrm{p}<1 \%$.

Source: $[45,46]$; authors' calculations. 
Table 3. Cross-Section Dependence Test.

\begin{tabular}{|c|c|c|c|c|c|c|}
\hline Test/variables & L(EDI) & L(RGC) & L(RGC) & L(FFEC) & L(RPC) & L(UPT) \\
\hline Breusch-Pagan LM & $238.84^{* * *}$ & $642.39^{* * *}$ & $645.81^{* * *}$ & $323.79^{* * *}$ & $181.11^{* * *}$ & $713.78^{* * *}$ \\
\hline Pesaran scaled LM & $19.38^{* * *}$ & $61.92^{* * *}$ & $62.28^{* * *}$ & $28.33^{* * *}$ & $13.29^{* * *}$ & $69.44^{* * *}$ \\
\hline Bias-corrected scaled LM & $19.12^{* * *}$ & $61.65^{* * *}$ & $62.01^{* * *}$ & $28.07^{* * *}$ & $13.03^{* * *}$ & $69.18^{* * *}$ \\
\hline Pesaran CD & $1.84^{*}$ & $24.82^{* * *}$ & $24.87^{* * *}$ & $4.33^{* * *}$ & $6.08^{* * *}$ & $8.31^{* * *}$ \\
\hline
\end{tabular}

Note: $\mathrm{L}$ - natural logarithm, significance levels: ${ }^{*} \mathrm{p}<10 \%,{ }^{* *} \mathrm{p}<5 \%,{ }^{* * *} \mathrm{p}<1 \%$.

Source: [45, 46]; authors' calculations.

for potential cross-sectional dependence. Hereafter, we carried out the logarithmic transformation of all of the inspected variables.

The Pesaran test was utilized to investigate the cross-sectional dependence in the relevant model (Eq. 2) [36]. Under the null hypothesis, there is no cross-sectional dependence, whereas the alternative declares the presence of cross-sectional dependence. Referring to the results in Table 3, the null hypothesis regarding the absence of cross-sectional dependence is strongly rejected for all of the inspected variables. Based on the findings (Table 3), it may be concluded that cross-sectional dependence exists, meaning that changes in the magnitude of the railway transport in one SEE economy might alter the magnitude of railway transport in another SEE economy.

In terms of the level of integration, this study utilizes the three relevant tests: Levin et al. - LLC [37], Phillips-Perron-Fisher Chi-square - PPF [38] and the cross-sectionally augmented Im-Pesaran-Shin (CIPS) [39]. Unit-root tests are utilized under the subsequent provisions: (1) only intercept and (2) intercept and trend, as displayed in Table 4.

Referring to these results, the stationary property of $E D I$ can be inferred at the log level in both cases: 1. intercept included; 2. intercept and trend included.

Table 4. Panel Unit-Root Analysis.

\begin{tabular}{|c|c|c|c|c|c|}
\hline \multirow{2}{*}{ Variables } & \multirow{2}{*}{ Test } & \multicolumn{2}{|c|}{ Levels } & \multicolumn{2}{|c|}{ First differences } \\
\hline & & Intercept & Intercept and trend & Intercept & Intercept and trend \\
\hline \multirow{3}{*}{ L(EDI) } & LLC & $-3.97^{* * *}$ & $-4.21^{* * *}$ & $-6.32^{* * * *}$ & $-5.80^{* * *}$ \\
\hline & PPF & $37.23^{* *}$ & $31.91^{* *}$ & $97.13^{* * *}$ & $123.40^{* * *}$ \\
\hline & CIPS & -1.38 & -2.26 & $-3.67^{* * *}$ & $-4.55^{* * *}$ \\
\hline \multirow{3}{*}{$\mathrm{L}(\mathrm{RGC})$} & LLC & -0.09 & 1.69 & $-2.10^{* *}$ & $-4.81^{* * *}$ \\
\hline & PPF & $33.80^{* *}$ & $32.98^{* *}$ & $324.69^{* * *}$ & $64.51^{* * *}$ \\
\hline & CIPS & $-2.25^{*}$ & -2.57 & $-3.84^{* * *}$ & $-4.41^{* *}$ \\
\hline \multirow{3}{*}{$\mathrm{L}(\mathrm{RGC})^{2}$} & LLC & -0.09 & 1.16 & $-2.85^{* * *}$ & $-4.78^{* * *}$ \\
\hline & PPF & $31.12^{*}$ & $33.98^{*}$ & $225.99^{* * * *}$ & $69.69^{* * *}$ \\
\hline & CIPS & -2.09 & -2.41 & $-3.71^{* * * *}$ & $-4.32^{* * *}$ \\
\hline \multirow{3}{*}{$\mathrm{L}(\mathrm{FFEC})$} & LLC & 1.50 & 0.55 & $-4.85^{* * *}$ & $-5.46^{* * *}$ \\
\hline & PPF & 18.70 & $30.70^{*}$ & $219.38^{* * *}$ & $115.61^{* * *}$ \\
\hline & CIPS & -1.53 & -2.70 & $-4.09^{* * *}$ & $-4.07^{* * *}$ \\
\hline \multirow{3}{*}{$\mathrm{L}(\mathrm{RPC})$} & LLC & $-1.99^{* *}$ & 0.74 & $-3.41^{* * *}$ & $-3.11^{* * *}$ \\
\hline & PPF & 26.82 & $34.76^{* *}$ & $212.64^{* * *}$ & $88.69^{* * *}$ \\
\hline & CIPS & -1.40 & -1.25 & $-3.19^{* * *}$ & $-3.36^{* *}$ \\
\hline \multirow{3}{*}{ L(UPT) } & LLC & $-6.10^{* * *}$ & -1.22 & -0.16 & -0.28 \\
\hline & PPF & $281.01^{* * *}$ & 16.69 & 11.09 & $30.17^{*}$ \\
\hline & CIPS & -0.66 & -2.13 & $-2.91^{* * *}$ & $-3.16^{* * *}$ \\
\hline
\end{tabular}

Note: Significance levels: ${ }^{*} \mathrm{p}<10 \%,{ }^{* *} \mathrm{p}<5 \%,{ }^{* * *} \mathrm{p}<1 \%$.

Source: [45, 46]; authors' calculations. 
Table 5. Results of Panel Cointegration Tests.

\begin{tabular}{|c|c|c|}
\hline Test & Statistic & Value \\
\hline \multirow{4}{*}{$\begin{array}{c}\text { Maddala and Wu } \\
\text { [33] }\end{array}$} & $\begin{array}{c}\text { Fisher (from trace } \\
\text { test) }\end{array}$ & $99.030^{* * *}$ \\
\cline { 3 - 3 } & & $489.800^{* * *}$ \\
\cline { 3 - 3 } & & $159.700^{* * *}$ \\
\cline { 3 - 3 } & & $84.420^{* * *}$ \\
\cline { 3 - 3 } & & $42.340^{* * *}$ \\
\hline \multirow{2}{*}{ Kao [32] } & $\mathrm{t}-\mathrm{stat}$ & $-6.301^{* * *}$ \\
\hline \multirow{3}{*}{ Westerlund [34] } & $\mathrm{Gt}$ & $-4.558^{* * *}$ \\
\cline { 3 - 3 } & $\mathrm{Ga}$ & -3.762 \\
\cline { 2 - 3 } & $\mathrm{Pt}$ & $-15.436^{* * *}$ \\
\cline { 2 - 3 } & $\mathrm{Pa}$ & -4.334 \\
\hline
\end{tabular}

Note: Significance levels: ${ }^{*} \mathrm{p}<10 \%, *{ }^{*} \mathrm{p}<5 \%, * * * \mathrm{p}<1 \%$. Source: $[45,46]$; authors' calculations.

However, the log levels of RPC and UPT are stationary only in the case when the intercept is included. The Phillips-Perron-Fisher Chi-square test shows the stationary properties of $E D I, R G C, R G C^{2}$ at the $\log$ levels in both cases: 1 . intercept included; 2 . intercept and trend included. FFEC and $R P C$ are stationary at the $\log$ levels in case 2. Intercept and trend are included while urbanization is stationary at level in the case when only the intercept is included. All of the inspected variables are, however, stationary at their first difference. The results obtained from the test, robust to cross-sectional dependence (CIPS), confirm these findings and suggest the stationary properties at first difference. In other words, it can be inferred that the inspected variables are integrated of the same order $I(1)$.

\section{Panel Cointegration}

To confirm the cointegration relationship between the observed variables, we utilize the relevant tests and display findings in Table 5. Yet, our tests conclude that the nexus amid environmental depletion, real GDP per capita, real GDP per capita squared, fossil fuel energy consumption, urbanization and transportation activity is defined as a long-term relationship.

\section{Long-Run and Short-Run Results}

After confirming the cointegration relationship, we apply FMOLS and the PMG estimators to determine the long-term regression parameters using Eq. 2. The findings on the long-term relationship between environmental depletion and relevant independent variables are shown in Table 6.

All of the variables, except for the real GDP per capita squared, have a significant positive impact on environmental depletion via the weighted version of the FMOLS estimation. However, the coefficient with the real GDP per capita square is significantly negative, thereby confirming the inverted U-shaped environmental depletion-growth nexus. In other words, the EKC framework exists in the SEE countries in the long-term, thereby validating our study's hypothesis and setting out the answer to RQ1. Table 6 also demonstrates a significant positive impact of fossil fuel energy consumption on environmental depletion. Consequently, a $1 \%$ increase in fossil fuel energy

Table 6. Long-Run Estimations via FMOLS and PMG.

\begin{tabular}{|c|c|c|}
\hline \multirow{2}{*}{ Estimation method/Variables } & FMOLS & \multirow{2}{*}{ PMG } \\
\cline { 2 - 3 } & Weighted & $1.554^{* * *}(0.287)$ \\
\hline L(RGC) & $1.244^{* * *}(0.023)$ & $-0.069^{* * *}(0.015)$ \\
\hline L(RGC $)$ & $-0.049^{* *}(0.024)$ & $2.159^{* * *}(0.067)$ \\
\hline L(FFEC) & $1.693^{* * *}(0.030)$ & $0.076^{* * *}(0.015)$ \\
\hline L(RPC) & $0.176^{* * *}(0.031)$ & $0.860^{* * *}(0.001)$ \\
\hline L(UPT) & $1.682^{* * *}(0.001)$ & $-0.928^{* * *}(0.245)$ \\
\hline ECT -1 & 10 & 10 \\
\hline Groups & 190 & 180 \\
\hline Observations & 0.964 & 0.090 \\
\hline R-squared & 2.557 & 504.799 \\
\hline Sum squared resid & & 109 \\
\hline Log likelihood & & \\
\hline
\end{tabular}

Note: Standard errors in parentheses. Significance levels: ${ }^{*} \mathrm{p}<10 \%, * * \mathrm{p}<5 \%, * * * \mathrm{p}<1 \%$. EDI is the dependent variable. Source: $[45,46]$; authors' calculations. 
consumption increases environmental depletion by $1.69 \%$. Similarly, urbanization is also reported to have a negative environmental effect, indicating that a $1 \%$ increase in the urban to total population increases environmental depletion by $1.68 \%$. Most importantly, railway transport has a significant positive impact on environmental depletion. This empirically means that a $1 \%$ increase in railways and passengers carried increases environmental depletion by $0.18 \%$. These findings set out the answer to RQ2.

Next, we employ the PMG estimator to check the robustness of the results following the estimation via FMOLS. The PMG estimation results reveal significant and positive coefficients with real GDP per capita, railway transport, urbanization and fossil fuel energy consumption, whereas the coefficient with real GDP per capita squared is found to be significantly negative in the long-run. The ECT in the model estimated using the PMG estimator is negatively significant, demonstrating that pollutant emissions converge to its long-term equilibrium path. In addition, the coefficient with ECT confirms the stability of the relationship in Eq. (2).

According to both the FMOLS and PMG results, the transport-induced EKC hypothesis exists in SEE countries. These findings affirm the evidence of [9, 14$16,18]$. The SEE countries have a significantly lower ecological footprint per capita than the countries of the European Union [35]. Despite their use of coal, Bosnia and Herzegovina has similar or lower per capita carbon emissions compared to the EU, while the remaining countries have far lower ones. The situation is the opposite regarding carbon emissions per unit of GDP: here, only Albania, due to its large share of renewable energy, is comparable to the European Union, while the other inspected countries are much less efficient in terms of their economic output in light of their level of emissions. Addressing the strong dependence of SEE countries on fossil fuel energy consumption, the positive coefficient with FFEC in Table 6 is unsurprising. The empirical results revealing a positive impact of fossil fuel energy consumption on environmental depletion are in line with the evidence provided by [15].

With the economic development resulting in an ongoing increase in economic activity, and also the negative consequences of consumer society, with the rapid urbanization, the increasing ownership of obsolete second-hand cars, and rapid increase in road transport are becoming visible, but the public seems to have accepted increasing pollution as a necessary by product of progress [35]. The quality of the information on air pollution and its accessibility has improved in recent years. Hence, the citizens have become more aware about the trends in air pollution. Accordingly, some emergency measures, such as car bans in urban areas, have also been introduced during the worst pollution episodes, although air quality remains the deadliest pollution-related problem in the observed countries. Consequently, the positive coefficient with urbanization and railway transport is not unexpected. The SEE
Table 7. The EKC in the Short-Run.

\begin{tabular}{|c|c|}
\hline Developing countries & EKC \\
\hline Albania & No \\
\hline Bulgaria & No \\
\hline Bosnia and Herzegovina & No \\
\hline Greece & No \\
\hline Croatia & Yes \\
\hline Moldova & No \\
\hline North Macedonia & No \\
\hline Romania & No \\
\hline Slovenia & No \\
\hline Turkey & Yes \\
\hline
\end{tabular}

Note: Obtained from PMG estimation.

Source: $[45,46]$; authors' calculations.

countries did not implement pollutant emission mitigation policies and taxation in the urbanized areas. This concluding remark is justified by [7, 9, 17]. In addition, the FMOLS and PMG results suggest a statistically significant positive impact of railway transport on pollutant emissions. Railway transport is an important economic activity in the SEE countries. Considering the related implications of railway transport, such as environmental degradation and noise, a negative environmental effect is anticipated and in line with [14, 17, 18].

The results of the PMG estimator are further employed to assess the environmental depletion-growth nexus in the short-term. The findings presented in Table 7 helped us to check the validity of transport-induced EKC phenomenon in the short-term by considering individual countries. The traditional transport-induced EKC theory, which has an inverted U-shaped curve, has also been confirmed in the overall panel of ten SEE economies as well as in the case of Croatia and Turkey in the short-run. Based on Table 7, the inverted U-shaped curve was not confirmed in the case of: Albania, Bulgaria, Bosnia and Herzegovina, Greece, Moldova, North Macedonia, Romania and Slovenia.

\section{Causality Analysis}

Finally, we inspect the long- and short-term causality. The results of the causality tests based on the panel VECM are briefly shown in Table 8 (the voluminous output of VECM estimation is available upon request).

There exists a two-way causal relationship between real GDP per capita and environmental depletion in the short-run. Our findings support the evidence presented by $[6,7,17,47]$. It is important to note the two-way causal relationship between fossil fuels energy consumption and environmental depletion. For this 
Table 8. Results of the Causality Tests Based on VECM.

\begin{tabular}{|c|c|c|c|c|c|c|c|}
\hline \multirow{2}{*}{$\begin{array}{l}\text { Dependent } \\
\text { variables }\end{array}$} & \multicolumn{6}{|c|}{ Short-run coefficients } & \multirow{2}{*}{$\begin{array}{c}\begin{array}{c}\text { Long-run } \\
\text { coefficients }\end{array} \\
\text { ECT }\end{array}$} \\
\hline & $\Delta \mathrm{L}(\mathrm{EDI})$ & $\Delta \mathrm{L}(\mathrm{RGC})$ & $\Delta \mathrm{L}\left(\mathrm{RGC}^{2}\right)$ & $\Delta \mathrm{L}(\mathrm{FFEC})$ & $\Delta \mathrm{L}(\mathrm{RPC})$ & $\Delta \mathrm{L}(\mathrm{UPT}$ & \\
\hline$\Delta \mathrm{L}(\mathrm{EDI})$ & - & $\begin{array}{c}-1.384^{* * *} \\
(-0.353)\end{array}$ & $\begin{array}{c}0.091 \\
(-0.962)\end{array}$ & $\begin{array}{c}0.072^{*} \\
(-0.041)\end{array}$ & $\begin{array}{l}-0.185^{* *} \\
(-0.084)\end{array}$ & $\begin{array}{c}-0.004 \\
(-0.001)^{* * *}\end{array}$ & $\begin{array}{c}-0.336 \\
{[-4.624]^{* * *}}\end{array}$ \\
\hline$\Delta \mathrm{L}(\mathrm{RGC})$ & $\begin{array}{l}5.940^{* * *} \\
(-1.303)\end{array}$ & - & $\begin{array}{c}-3.340 \\
(-11.819)\end{array}$ & $\begin{array}{l}1.910^{* * *} \\
(-0.509)\end{array}$ & $\begin{array}{l}12.661^{*} \\
(-7.001)\end{array}$ & $\begin{array}{c}0.018 \\
(-0.014)\end{array}$ & $\begin{array}{c}-0.101 \\
{[-2.732]^{* * *}}\end{array}$ \\
\hline$\Delta \mathrm{L}\left(\mathrm{RGC}^{2}\right)$ & $\begin{array}{c}-0.323^{* * *} \\
(-0.076)\end{array}$ & $\begin{array}{c}-0.024 \\
(-0.038)\end{array}$ & - & $\begin{array}{c}-0.103^{* * *} \\
(-0.029)\end{array}$ & $\begin{array}{l}-0.732^{*} \\
(-0.407)\end{array}$ & $\begin{array}{c}-0.001 \\
(-0.001)\end{array}$ & $\begin{array}{c}-1.516 \\
{[-2.303]^{* *}}\end{array}$ \\
\hline$\Delta \mathrm{L}(\mathrm{FFEC})$ & $\begin{array}{l}0.823^{* * *} \\
(-0.262)\end{array}$ & $\begin{array}{c}0.319^{* *} \\
(-0.133)\end{array}$ & $\begin{array}{c}5.219^{* *} \\
(-2.378)\end{array}$ & - & $\begin{array}{l}-5.058^{* * *} \\
(-1.409)\end{array}$ & $\begin{array}{l}-0.005^{*} \\
(-0.003)\end{array}$ & $\begin{array}{c}-0.139 \\
{[-4.897]^{* * *}}\end{array}$ \\
\hline$\Delta \mathrm{L}(\mathrm{RPC})$ & $\begin{array}{c}0.058 \\
(-0.053)^{*}\end{array}$ & $\begin{array}{c}0.048^{*} \\
(-0.026)\end{array}$ & $\begin{array}{c}0.803^{*} \\
(-0.482)\end{array}$ & $\begin{array}{c}-0.277^{* * *} \\
(-0.102)\end{array}$ & - & $\begin{array}{c}-0.001 \\
(-0.001)\end{array}$ & $\begin{array}{c}-19.983 \\
{[-5.343]^{* * *}}\end{array}$ \\
\hline$\Delta \mathrm{L}(\mathrm{UPT})$ & $\begin{array}{c}11.172 \\
(-6.774)^{*}\end{array}$ & $\begin{array}{c}2.592 \\
(-3.436)\end{array}$ & $\begin{array}{c}48.534 \\
(-61.428)\end{array}$ & $\begin{array}{l}-0.044^{* *} \\
(-0.021)\end{array}$ & $\begin{array}{c}-2.703 \\
(-36.392)\end{array}$ & - & $\begin{array}{c}0.004 \\
{[5.203]^{* * *}}\end{array}$ \\
\hline Observations & & & 160 & & & & \\
\hline R-squared & 0.537 & 0.288 & 0.265 & 0.468 & 0.811 & 0.359 & \\
\hline S.E. of regression & 0.079 & 0.040 & 0.714 & 0.031 & 0.423 & 0.001 & \\
\hline F-statistic & 12.030 & 4.181 & 3.728 & 9.109 & 44.465 & 5.801 & \\
\hline Log likelihood & 187.573 & 296.193 & -165.200 & 338.138 & -81.437 & 913.547 & \\
\hline
\end{tabular}

Note: Standard errors are presented in parentheses and the t-statistics in brackets. ECT represents the error correction term.

Significance levels: ${ }^{*} \mathrm{p}<10 \%, * * \mathrm{p}<5 \%,{ }^{* * *} \mathrm{p}<1 \%$.

Source: $[45,46]$; authors' calculations.

relationship, $[6,10,14]$ demonstrated equivalent output. Our causality results imply a bidirectional causal linkage amid urbanization and environmental depletion. These findings are in line with [17]. Lastly, a twoway causal relationship between transport activity and environmental depletion is supported by the findings of [17] and [14].

As illustrated in Table 8 , there is evidence of a two-way causal relationship between urbanization and pollutant emission in the short-run. This finding aligns with [48]. Affluence is reported to have a one-way causal relationship with pollutant emissions in the shortrun. This evidence is also confirmed by [49]. Finally, the long-run coefficients show that pollutant emissions converge to equilibrium with respect to the changes in affluence and energy consumption. This evidence is strongly supported by $[50,51]$. The VEC residual serial correlation $\mathrm{p}$-value does not reject the null hypothesis regarding an absence of serial correlation.

\section{Conclusions}

This present study augmented the theme of the EKC framework by focusing on the role of transportation activity. It evaluated whether affluence, fossil fuel energy consumption, urbanization and transportation activity exert significant long-term effects on environmental depletion in the case of ten
SEE countries for the period 1995-2014. Accordingly, it specifically emphasized the impact of various macroeconomic variables on environmental degradation by utilizing cross-sectional dependence tests, relevant unit root tests, panel cointegration tests as well as PMG and FMOLS estimators to evaluate the long-term relationships. To determine the direction of the causality between the inspected variables in the short- and longterm, we needed to use the panel vector error correction model (VECM) and Granger causality test.

The cross-section dependence test revealed that the null hypothesis regarding a lack of cross-sectional dependence is strongly refuted. The relevant unit root tests confirm the stationary properties of all of the variables at first differences. The cointegration tests highlight that the null hypothesis regarding a lack of cointegration is strongly rejected the existence of long-run associations between the inspected variables. After validating the cointegration relationship, this study further utilized relevant panel data estimators to calculate the regression coefficients. According to both of the FMOLS and PMG outcomes, the inverted U-shaped relationship between affluence and environmental depletion is verified, confirming the existence of the EKC hypothesis for the sample of ten SEE countries in the long-term. Transport activity has negative environmental effects in the long-term. Based on the PMG findings, the EKC phenomenon is affirmed only for Croatia and Turkey in the short-term, whereas 
the other countries do not report an inverted U-shaped relationship between affluence and environmental depletion in the short-term. Finally, the Granger causality test outlines the two-way causal relationship between affluence and carbon emissions; fossil fuel energy consumption and carbon emissions; railway transport and carbon emissions; and urbanization and carbon emissions. Overall, these macroeconomic variables do not reduce environmental depletion in the long-term in the inspected sample of countries.

Our empirical results recommend certain policies. A positive impact of fossil fuel energy consumption on environmental depletion raises the necessity of reducing the traditional energy consumption without jeopardizing the economic performance of the SEE economies. In this regard, it is vital to increase energy efficiency, energy savings, investments in clean energy sources and cleaner technologies. Addressing the strong dependence on fossil fuels, there is a dire need to implement renewable energy sources in SEE countries. In such a case, that provides a positive relationship between transport and environmental depletion, it is vital to balance transportation needs with clean energy objectives. In addition, policy makers should implement relevant strategies that will help to increase the energy efficiency in the transportation sector.

Some limitations of our study are considered as follows. Firstly, the prediction of the EKC framework is limited to the case of ten SEE countries only and these findings are certainly not generalizable. Secondly, there are other proxies for transport activity, e.g., (passenger) air transport that could be employed to provide a better understating of the transport-induced EKC model. Thirdly, not only transportation but also other economic activities, such as tourism, industry and manufacturing, might be examined in order to gain further insights into the environmental depletionaffluence nexus.

\section{Acknowledgments}

We would like to thank reviewers for their valuable comments that enabled us to improve the manuscript.

\section{Conflict of Interest}

The authors declare no conflict of interest.

\section{References}

1. KAHN R.S., KOBAYASHI S., BEUTHE M., GASCA J., GREENE D., LEE D.S., MUROMACHI Y., NEWTON P.J., PLOTKIN S., SPERLING D., WIT R., ZHOU P.J. Transport and its infrastructure. In Climate Change; Metz B., Davidson O.R., Bosch P.R., Dave R., Meyer L.A., Eds., Cambridge University Press: Cambridge, United Kingdom and New York, USA, 2007.
2. IEA. CO2 emissions from fuel combustion 2019 highlights. Available online: http:// wds.iea.org/wds/pdf/Worldco2_ Documentation.pdf (accessed on 0512 2020).

3. KUZNETS S. Economic growth and income inequality. The American Economic Review. 45, 1, 1955.

4. GROSSMAN G.M., KRUEGER A. Environmental impacts of North America's free trade Agreement. NBER Working Paper, 3914, 1991.

5. INCEKARA C.O. Use of an optimization model for optimization of Turkey's energy management by inclusion of renewable energy sources. International Journal of Environmental Science and Technology. 16, 6617, 2019.

6. SHAHBAZ M., KHRAIEF N., JEMAA M.M.B. On the causal nexus of road transport $\mathrm{CO} 2$ emissions and macroeconomic variables in Tunisia: Evidence from combined cointegration tests. Renewable and Sustainable Energy Reviews. 51, 89, 2015.

7. PRASTIYO S.E., IRHAM I., HARDYASTUTI S., JAMHARI J. How agriculture, manufacture, and urbanization induced carbon emission? The case of Indonesia. Environmental Science and Pollution Research. 27, 42092, 2020.

8. BEN ABDALLAH K., BELLOUMI M., DE WOLF D. Indicators for sustainable energy development: A multivariate cointegration and causality analysis from Tunisian road transport sector. Renewable and Sustainable Energy Reviews. 25, 34, 2013.

9. KHARBACH M., CHFADI T. $\mathrm{CO}_{2}$ emissions in Moroccan road transport sector: Divisia, Cointegration, and EKC analyses. Sustainable Cities and Society. 35, 396, 2017.

10. ALSHEHRY A.S., BELlOUMI M. Study of the environmental Kuznets curve for transport carbon dioxide emissions in Saudi Arabia. Renewable and Sustainable Energy Reviews. 75, 1339, 2017.

11. GO Y.H., LAU L.S., LIEW F.M., SENADJKI A. A transport environmental Kuznets curve analysis for Malaysia: exploring the role of corruption. Environmental Science and Pollution Research. 28, 3421, 2020.

12. OZDEN C., BESE E. Environmental Kuznets curve (EKC) in Australia: Evidence from nonlinear ARDL model with a structural break. Polish Journal of Environmental Studies. 30 (3), 2245, 2021.

13. FAHAD S., WANG J. Climate change, vulnerability, and its impacts in rural Pakistan: a review. Environmental Science and Pollution Research. 27, 1334, 2020.

14. OZKAN T., YANGINLAR G., KALAYCI S. Testing the transportation-induced environmental Kuznets curve hypothesis: Evidence from eight developed and developing countries. International Journal of Energy Economics and Policy. 9 (1), 174, 2019.

15. ERDOGAN S., FATAI ADEDOYIN F., VICTOR BEKUN F., ASUMADU SARKODIE S. Testing the transportinduced environmental Kuznets curve hypothesis: The role of air and railway transport. Journal of Air Transport Management. 89, 101935, 2020.

16. MANTA A.G., FLOREA N.M., BĂDÎRCEA R.M., POPESCU J., CÎRCIUMARU D., DORAN M.D. The nexus between carbon emissions, energy use, economic growth and financial development: evidence from central and eastern European countries. Sustainability. 12 (18), $7747, \mathbf{2 0 2 0}$

17. ARVIN M.B., PRADHAN R.P., NORMAN N.R. (2015). Transportation intensity, urbanization, economic growth, and $\mathrm{CO}_{2}$ emissions in the G-20 countries. Utilities Policy. 35, 50, 2015. 
18. KALAYCI S. Analysing transportation-induced economic growth, energy use, and $\mathrm{CO}_{2}$ emissions: An empirical investigation from EU countries. In Handbook of Research on the Applications of International Transportation and Logistics for World Trade; Çiçek C.G., Ed. IGI Global: Hershey, USA, 2020.

19. MEHMOOD U., TARIQ S. Globalization and $\mathrm{CO}_{2}$ emissions nexus: evidence from the EKC hypothesis in South Asian countries. Environmental Science and Pollution Research. 27, 37044, 2020.

20. ANSER M.K., KHAN M.A., NASSANI A.A., ABRO M.M.Q., ZAMAN K., KABBANI A. Dynamic linkages between green energy, knowledge spillover, and carbon emissions: Global evidence. Polish Journal of Environmental Studies. 30 (4), 1, 2021.

21. AHMAD M., MUSLIJA A., SATROVIC E. Does economic prosperity lead to environmental sustainability in developing economies? Environmental Kuznets curve theory. Environmental Science and Pollution Research. 28, 22588, 2021.

22. HUSKIC M., SATROVIC E. Human developmentrenewable energy-growth nexus in the top 10 energy gluttons. Administration. 22, 25, 2020.

23. VERBIČ M., SATROVIC E., MUSLIJA A. Environmental Kuznets curve in Southeastern Europe: the role of urbanization and energy consumption. Environmental Science and Pollution Research, 2021. https://oi. org/10.1007/s11356-021-14732-6

24. MURSHED M., ABBASS K., RASHID S. Modelling renewable energy adoption across south Asian economies: empirical evidence from Bangladesh, India, Pakistan and Sri Lanka. International Journal of Finance and \& Economics, 2020. https://doi.org/10.1002/ijfe.2073

25. IQBAL N., ABBASI K.R., SHINWARI R., GUANGCAI W., AHMAD M., TANG K. Does exports diversification and environmental innovation achieve carbon neutrality target of OECD economies? Journal of Environmental Management, 291, 112648, 2021.

26. SATROVIC E., AHMAD M., MUSLIJA A. Does democracy improve environmental quality of GCC region? Analysis robust to cross-section dependence and slope heterogeneity. Environmental Science and Pollution Research, 2021. https://doi.org/10.1007/s11356-021-15020-z

27. MEHMOOD U. Contribution of renewable energy towards environmental quality: The role of education to achieve sustainable development goals in G11 countries. Renewable Energy, 178, 600, 2021.

28. SATROVIC E., MUSLIJA A. Economic and demographic determinants of the demand for life insurance: Multivariate analysis. Journal of Management and Economics Research. 16, 102, 2018.

29. AHMAD M., ZHAO Z.Y. Empirics on linkages among industrialization, urbanization, energy consumption, $\mathrm{CO} 2$ emissions and economic growth: A heterogeneous panel study of China. Environmental Science and Pollution Research. 25, 30617, 2018.

30. SATROVIC E., MUSLIJA A. The empirical evidence on tourism-urbanization- $\mathrm{CO}_{2}$ emissions nexus. Advances in Hospitality and Tourism Research (AHTR). 7 (1), 85, 2019.

31. MUJTABA A., JENA P.K., MUKHOPADHYAY D. Determinants of $\mathrm{CO}_{2}$ emissions in upper middle-income group countries: an empirical investigation. Environmental Science and Pollution Research. 27, 37745, 2020.

32. MUNIR S., KHAN A. Impact of fossil fuel energy consumption on $\mathrm{CO}_{2}$ emissions: Evidence from Pakistan
(1980-2010). The Pakistan Development Review. 53 (4), 327, 2014.

33. SATROVIC E. Energy consumption, trade openness and growth nexus in Turkey: evidence from VECM. Journal of Economics and Administrative Sciences. 20 (1), 1, 2019.

34. JELAVICH B. History of the Balkans: Eighteenth and Nineteenth Centuries; Cambridge University Press: Cambridge, 1983.

35. UN ENVIRONMENT. Pollution in the EWestern Balkans. UN Environment: Belgrade, 2018.

36. PESARAN M.H. General diagnostic test for cross section dependence in panels. IZA Working Paper, 1240, 2004.

37. LEVIN A., LIN C.F., CHU C.S.J. Unit root tests in panel data: Asymptotic and finite-sample properties. Journal of Econometrics. 108 (1), 1, 2002.

38. CHOI I. Unit root tests for panel data. Journal of International Money and Finance. 20 (2), 249, 2001.

39. PESARAN M.H. A simple panel unit root test in the presence of cross-section dependence. Journal of Applied Econometrics. 22, 265, 2007.

40. KAO C. Spurious regression and residual-based tests for cointegration in panel data. Journal of Econometrics. 90 (1), 1, 1999.

41. MADDALA G.S., WU S. A comparative study of unit root tests with panel data and a new simple test. Oxford Bulletin of Economics and Statistics. 61 (s1), 631, 1999.

42. WESTERLUND J. Testing for error correction in panel data. Oxford Bulletin of Economics and Statistics. 69 (6), 709, 2007.

43. PEDRONI P. Fully modified OLS for heterogeneous cointegrated panels. In Nonstationary Panels, Panel Cointegration and Dynamic Panels; Baltagi B.H., Ed. JAI Press: Amsterdam, 2000.

44. PESARAN M.H., SHIN Y., SMITH, R.P. Pooled mean group estimation of dynamic heterogeneous panels. Journal of the American Statistical Association. 94 (446), 621, 1999.

45. WORLD BANK. World Development Indicators 10/15/2020. Available online: https://databank.worldbank. org/source/world-development-indicators (accessed on 11 11 2020).

46. OECD. Passenger transport (indicator). Available online: https://data.oecd.org/transport/passenger-transport.htm (accessed on 1103 2021).

47. SATROVIC E., MUSLIJA A., ABUL S.J. The relationship between $\mathrm{CO} 2$ emissions and gross capital formation in Turkey and Kuwait. The South East European Journal of Economics and Business. 15 (2), 28, 2020.

48. YAZDI S.K., DARIANI A.G. $\mathrm{CO}_{2}$ emissions, urbanisation and economic growth: evidence from Asian countries. Economic Research. 32 (1), 510, 2019.

49. AYE G.C., EDOJA P.E. Effect of economic growth on $\mathrm{CO}_{2}$ emission in developing countries: Evidence from a dynamic panel threshold model. Cogent Economics \& Finance. 5 (1), 1379239, 2017.

50. OZATAC N., GOKMENOGLU K.K., TASPINAR N. Testing the EKC hypothesis by considering trade openness, urbanization, and financial development: the case of Turkey. Environmental Science and Pollution Research. 24, 16690, 2017.

51. ADEDOYIN F.F., ZAKARI A. Energy consumption, economic expansion, and $\mathrm{CO}_{2}$ emission in the UK: The role of economic policy uncertainty. Science of The Total Environment, 2020. https://doi.org/10.1016/j. scitotenv.2020.140014 